\title{
Use of bromodeoxyuridine immunocapture to identify psychrotolerant phenanthrene-degrading bacteria in phenanthrene-enriched polluted Baltic Sea sediments
}

\author{
Anna Edlund ${ }^{1,2}$ \& Janet K. Jansson ${ }^{2,3}$ \\ ${ }^{1}$ University College, School of Life Sciences, Huddinge, Sweden; \\ ${ }^{2}$ Swedish University of Agricultural Sciences, Department of Microbiology, Uppsala, Sweden; \\ ${ }^{3}$ Lawrence Berkeley National Laboratory, Earth Sciences Division, Berkeley, CA, USA
}

Keywords: phenanthrene; bromodeoxyuridine; terminalrestriction fragment length polymorphism; Baltic Sea sediment; Exiguobacterium

\begin{abstract}
The aim of this study was to enrich and identify psychrotolerant phenanthrenedegrading bacteria from polluted Baltic Sea sediments. Polyaromatic hydrocarbon (PAH)-contaminated sediments were spiked with phenanthrene and incubated for 2 months in the presence of bromodeoxyuridine that is incorporated into the DNA of replicating cells. The bromodeoxyuridine-incorporated DNA was extracted by immunocapture and analyzed by terminal-restriction fragment length polymorphism and 16S rRNA gene cloning and sequencing to identify bacterial populations that were growing. In addition, degradation genes were quantified in the bromodeoxyuridine-incorporated DNA by real-time PCR. Phenanthrene concentrations decreased after 2 months of incubation in the phenanthrene-enriched sediments and this reduction correlated to increases in copy numbers of xylE and phnAc dioxygenase genes. Representatives of Exiguobacterium, Schewanella,Methylomonas, Pseudomonas, Bacteroides and an uncultured Deltaproteobacterium and a Gammaproteobacterium dominated the growing community in the phenanthrenespiked sediments. Isolates that were closely related to three of these bacteria (two pseudomonads and an Exiguobacterium sp.) could reduce phenanthrene concentrations in pure cultures and they all harbored phnAc dioxygenase genes. These results confirm that this combination of culture-based and molecular approaches was useful for identification of actively growing bacterial species with a high potential for phenanthrene degradation.
\end{abstract}

\section{Introduction}

High concentrations of polyaromatic hydrocarbons (PAHs) have accumulated in sediments of some coastal regions of the Baltic Sea as a result of industrial activities. For example, sediments from the bay of O" rserumsviken, located on the southeast coast of Sweden, were highly contaminated with PAHs, polychlorinated biphenyls (PCBs) and mercury $(\mathrm{Hg})$ from paper mill operations between 1915 and 1980 (Palm et al., 2001). O" rserumsviken was therefore the focus of a large Swedish remediation initiative from 2001 to 2003, whereby the contaminated sediments were removed by dredging. The dredging project was successful, and only low levels of pollutants could be detected in the sediments following dredging (Edlund \& Jansson, 2006). In a previous study, we found that the total and actively growing bacterial communities in the polluted sediments in the bay before dredging were significantly different from those present in the bay after the polluted surface sediment layers were removed (Edlund \& Jansson, 2006). A few bacterial isolates that could transform phenanthrene to a colored intermediate on agar medium were obtained from the polluted sediments (Edlund \& Jansson, 2006).

Our aim here was to use a combination of molecular and cultivation-based approaches to further evaluate the intrinsic microbial potential for phenanthrene degradation in polluted Baltic Sea sediments. First, we enriched phenanthrenedegrading bacterial populations by spiking $\mathrm{PAH}$-contaminated sediments that were collected previously from O" rserumsviken with phenanthrene. To specifically identify metabolically active bacterial populations stimulated to grow in the presence of 
phenanthrene, we used bromodeoxyuridine immunocapture as a molecular tool that does not rely on cultivation for identification of growing bacteria and that was also successfully used previously for identification of active bacterial populations in sediments (Edlund \& Jansson, 2006; Edlund et al., 2008). The reason for using a cultivation-independent method was to overcome the known biases of cultivationbased approaches that normally detect only a fraction of the microorganisms inhabiting natural communities. Also, our recent studies using molecular approaches have shown that the microbial diversity of Baltic Sea sediments is still largely unexplored, with relatively few 16S rRNA genes representative of cultured microorganisms in existing databases (Edlund et al., 2006, 2008). The bromodeoxyuridine immunocapture approach relies on the addition of bromodeoxyuridine as a thymidine analog that is incorporated into the DNA of replicating cells. The bromodeoxyuridineincorporated DNA is extracted from bulk DNA extracts by immunocapture onto magnetic beads (Urbach et al., 1999; Artursson \& Jansson, 2003; Edlund \& Jansson, 2006; Edlund et al., 2008) and the bacterial community composition of the bromodeoxyuridine-incorporated DNA can then be determined by terminal-restriction fragment length polymorphism (T-RFLP), and cloning and sequencing of 16S rRNA genes (Edlund \& Jansson, 2006; Edlund et al., 2008). In addition, we aimed to quantify levels of bromodeoxyuridine-labeled functional genes reported to be involved in $\mathrm{PAH}$ degradation (Simon et al., 1993; Kim \& Zylstra, 1995; Lauri \& Lloyd-Jones, 1999) by real-time PCR in the spiked sediments.

The second approach was to study isolates obtained previously from the contaminated sediments to evaluate their ability to degrade phenanthrene as a sole carbon and energy source and for the presence of PAH degradation genes in their genomes. In particular, we focused on isolates that, based on their $16 \mathrm{~S}$ rRNA gene sequences, were represented as potentially growing members of the sediment microbiota in the phenanthrene-enriched sediments using the molecular approaches described above.

The experiments were carried out at temperatures typical of the Baltic Sea site of origin, i.e. $5^{\circ} \mathrm{C}$. The results of this study therefore provide information about the identities of psychrotolerant bacteria that have potential for phenan- threne degradation in cold Baltic Sea sediments. We also obtained information regarding which genes and degradation pathways were present after long-term exposure to $\mathrm{PAH}$ compounds in cold aquatic habitats. This information is valuable for optimization of remediation of other PAHcontaminated environments in the Baltic Sea area and other cold regions.

\section{Materials and methods}

\section{Sediment collection and microcosm setup}

Polluted surface sediments were collected on October 5, 2002 from Örserumsviken (Edlund \& Jansson, 2006) and stored frozen at $-80^{\circ} \mathrm{C}$ after collection. Three sediment cores from four separate sampling stations in the bay (Edlund \& Jansson, 2006) were thawed at $4{ }^{\circ} \mathrm{C}$ overnight. The most dominant bacterial community members in all of these sediment cores were previously shown to be similar using a molecular fingerprinting approach (Edlund \& Jansson, 2006). One hundred and thirty milliliters of sediment were taken from each of the 12 sediment cores, pooled to a volume of $1.56 \mathrm{~L}$ and thoroughly mixed with a spoon. Fifty-milliliter portions of the pooled sediments were aliquoted into 200-mL Pyrex flasks with tightened screw caps. Phenanthrene was dissolved in acetone and added to a subsample of sediment $(25 \%$ of the total sediment volume). The acetone was evaporated before mixing with the remaining sediment, according to Brinch et al. (2002) to avoid impact of the solvent on the subsequent experiments. Phenanthrene was added to a final concentration of $10 \mu \mathrm{g} \mathrm{mL}^{-1}$ and $1 \mathrm{~mL}$ of $2 \mathrm{mM}$ Bromodeoxyuridine (Roche, Mannheim, Germany) was added to relevant treatments. Details of treatments and experimental replication are shown in Table 1. The sediment microcosms were incubated in the dark at $5{ }^{\circ} \mathrm{C}$ (the in situ temperature of the sediments at the sampling location) for a period of 60 days. Sampling of microcosms (see details below) was performed on days $0,1,2,7$ and 60 of incubation. All microcosms were gently stirred with a sterile spatula at each sampling period and also when bromodeoxyuridine was added.

Table 1. Sediment microcosm treatments

\begin{tabular}{llll}
\hline $\begin{array}{l}\text { Treatment } \\
\text { number (replicates) }\end{array}$ & $\begin{array}{l}\text { Phenanthrene addition } \\
\text { (day added) }\end{array}$ & $\begin{array}{l}\text { Bromodeoxyuridine } \\
\text { addition (day added) }\end{array}$ & Comments \\
\hline $1(3)$ & - & - & Negative control, used for total community DNA extraction \\
$2(6)$ & - & Day 0 & Control to identify active bacteria without added phenanthrene \\
$3(6)$ & Day 0 & Day 0 & Both phenanthrene and bromodeoxyuridine added at start of experiment \\
$4(3)$ & Day 0 & Days 0, 1,6 & Test repeated doses of bromodeoxyuridine in presence of phenanthrene \\
$5(3)$ & Day 0 & Day 58 & Test effect of bromodeoxyuridine addition 2 days prior to last sampling date \\
\hline
\end{tabular}




\section{Quantification of phenanthrene by GC-MS}

The total phenanthrene concentration was determined using the protocol developed by Pizzul et al. (2006) with the following modifications for pure cultures: $1 \mathrm{~mL}$ toluene was added to a $1-\mathrm{mL}$ sample in $3-\mathrm{mL}$ glass tubes with Teflonlined caps. The tubes were shaken vigorously for $20 \mathrm{~h}$ at 200 r.p.m. and the extracts were centrifuged for $10 \mathrm{~min}$ at $492 \mathrm{~g}$. After centrifugation, the supernatants were analyzed directly by GC-MS on an HP-5MS capillary column (250$\mu \mathrm{m}$ inner diameter, $30-\mathrm{m}$ length, $0.25-\mu \mathrm{m}$ nominal) (Agilent Technologies, Palo Alto, CA) using an HP 6890 Mass Selective Detector. The oven program was: $150^{\circ} \mathrm{C}$ for $2 \mathrm{~min}$, followed by ramping at $5{ }^{\circ} \mathrm{Cmin}^{-1}$ up to $250^{\circ} \mathrm{C}$ maintained for $5 \mathrm{~min}$. The injector temperature was $250^{\circ} \mathrm{C}$. The same procedure was used for sediment samples, except that $5 \mathrm{~mL}$ toluene was added to $15-\mathrm{mL}$ glass tubes with Teflon-lined caps containing a 5-mL sediment sample, the supernatants were diluted 10 times in toluene before analysis and GC-MS was performed on an HP 19091S-433 capillary column $(0.25 \mathrm{~mm}$ inner diameter, $30 \mathrm{~m}$ length, $0.25 \mathrm{~cm}$ thickness) (Agilent Technologies) using an HP 5971 Mass Selective Detector, and the oven program was: $80^{\circ} \mathrm{C}$ for $4 \mathrm{~min}$, followed by ramping at $7^{\circ} \mathrm{C} \mathrm{min}^{-1}$ up to $310^{\circ} \mathrm{C}$ maintained for $4 \mathrm{~min}$.

Identification and quantification of phenanthrene was performed by comparisons with external standards ranging from 0.5 to $10 \mu \mathrm{g}$ phenanthrene $\mathrm{mL}^{-1}$. The recovery of phenanthrene in freshly spiked uninoculated controls was $>95 \%$. The background level of phenanthrene in the sediment was $0.2 \mu \mathrm{g} \mathrm{mL}^{-1}$ sediment slurry.

\section{DNA extraction and bromodeoxyuridine- immunocapture}

DNA from metabolically active bacteria (i.e. replicating bacteria) was extracted using the bromodeoxyuridine immunocapture approach (Urbach et al., 1999; Artursson \& Jansson, 2003; Edlund \& Jansson, 2006; Edlund et al., 2006, 2008). This method relies on incorporation of bromodeoxyuridine as a thymidine analog into growing cells during DNA replication. Total DNA was extracted from $0.5-\mathrm{mL}$ sediment samples using a FastDNA ${ }^{\circledR}$ SPIN ${ }^{\mathbb{R}}$ Kit (for soil) following the manufacturer's instructions (Q-BIOgene, Carlsbad, CA). DNA with incorporated bromodeoxyuridine was purified by immunocapture using antibodies against bromodeoxyuridine (Urbach et al., 1999; Artursson \& Jansson, 2003; Edlund \& Jansson, 2006; Edlund et al., 2008). Monoclonal anti-bromodeoxyuridine antibodies ( $3 \mu \mathrm{L}$; Roche, Basel, Switzerland) were mixed at a 1:9 ratio with sheared and denatured herring sperm DNA ( $1.25 \mathrm{mg} \mathrm{mL}^{-1}$ in PBS; Promega, Madison, WI) to block nonspecific binding. The mixture was incubated for $30 \mathrm{~min}$ at room temperature. Magnetic beads (Dynabeads) coated with goat anti-mouse immunoglobulin G (DYNAL, Oslo, Norway) were washed three times with $1 \mathrm{mg} \mathrm{mL}^{-1}$ acetylated bovine serum albumin (BSA) in phosphate-buffered saline (PBS) buffer (PBS-BSA) using a magnetic particle concentrator (DYNAL) and re-suspended in PBS-BSA to the initial concentration. A $25-\mu \mathrm{L}$ portion of sediment DNA $(c .1 \mu \mathrm{g})$ was denatured (heated for $5 \mathrm{~min}$ at $100^{\circ} \mathrm{C}$, quickly transferred to ice and kept on ice for $5 \mathrm{~min}$ ), mixed with $30 \mu \mathrm{L}$ of the herring sperm DNA antibody mixture and incubated for $1 \mathrm{~h}$ in the dark at room temperature with constant agitation. The samples were mixed with $25-\mu \mathrm{L}$ portions of Dynabeads and the incubation was continued for an additional $1 \mathrm{~h}$. After incubation, the samples containing the Dynabeads, bromodeoxyuridine-labeled DNA and unlabeled DNA were washed five times in $0.5 \mathrm{~mL}$ PBS-BSA. After every wash, unlabeled DNA (i.e. DNA that did not bind to the beads) was discarded. To elute the remaining bromodeoxyuridinecontaining DNA fraction, $100 \mu \mathrm{L}$ of $1.7 \mathrm{mM}$ bromodeoxyuridine (in PBS-BSA) was added, and the samples were incubated for $1 \mathrm{~h}$ in the dark at room temperature with constant agitation. Two microliters of glycogen $(20 \mathrm{mg}$ $\mathrm{mL}^{-1}$; GE Healthcare, Bio-Sciences, NJ) were added to the bead supernatants and DNA was isolated by two rounds of ethanol precipitation and dissolved in $20 \mu \mathrm{L}$ of steriledistilled water. The DNA was washed using a QIAamp ${ }^{\circledR}$ DNA Micro Kit (QIAGEN, Hilden, Germany) according to the manufacturer's instructions, before PCR amplification.

The efficacy of bromodeoxyuridine immunocapture was confirmed by comparing visible bands on agarose gels after DNA extraction, immunocapture and PCR amplification with control sediment samples to which no bromodeoxyuridine was added. No PCR amplified product was visible in the controls without bromodeoxyuridine, demonstrating that the extraction was successful.

\section{T-RFLP}

Bacterial 16S rRNA gene sequences were PCR amplified from the bromodeoxyuridine-immunocaptured DNA using the following bacterial primers: fD1-Hex AGAGTTTGAT CMTGGCTCAG (Weisburg et al., 1991) labeled at the $5^{\prime}$-end with hexachlorofluorescein, and 926r CCGTCA ATTCCTTTRAGTTT (Muyzer et al., 1995). The PCR products $(12 \mu \mathrm{L}, c .20 \mathrm{ng}$ DNA) were digested for $2 \mathrm{~h}(50 \mu \mathrm{L}$ total volume) using HhaI restriction enzyme (Promega). The lengths of the fluorescent terminal restriction fragments (TRFs) were determined using an ABI capillary sequencer (Applied Biosystems, Foster City, CA) as described previously (Hjort et al., 2007). The sizes of the TRFs were determined by comparison with the internal GS ROX-500 size standard (Applied Biosystems). Before injection, $1.4 \mu \mathrm{L}$ of the DNA was denatured in the presence of $10 \mu \mathrm{L} \mathrm{Hi}-\mathrm{Di}^{\mathrm{TM}}$ formamide and $0.04 \mu \mathrm{L}$ GS ROX-500 size standard at $95^{\circ} \mathrm{C}$ 
for $5 \mathrm{~min}$. Injection was performed electrokinetically at $10 \mathrm{kV}$ for $50 \mathrm{~s}$ and the electrophoresis was run at $7.5 \mathrm{kV}$ for 179 min. Relative peak areas for TRFs were determined by dividing the individual TRF area by the total area of peaks within the thresholds of 60-490 bp. Only peaks with relative fluorescence intensities over $50 \mathrm{U}$ and that contributed to the total community abundance with $1.5 \%$ or more were included in the later analyses.

Diversity, defined as evenness and richness of the bacterial community members detected as TRFs by T-RFLP analysis, was calculated using Shannon's diversity and equitability index (Margalef, 1958).

\section{Cloning and sequencing}

Bacteria that were stimulated to grow in the phenanthreneenriched sediments after 60 days of incubation were identified by cloning and sequencing of $16 \mathrm{~S}$ rRNA genes that were amplified from bromodeoxyuridine-immunocaptured DNA from microcosms treated with phenanthrene and bromodeoxyuridine (treatment 3; Table 1) using the same primers as in T-RFLP. The PCR amplified products from bromodeoxyuridine-immunocaptured DNA extracted from the three replicate microcosms were pooled together before library construction. Ten nanograms of the amplified, $c$. 900-bp, bromodeoxyuridine-incorporated 16S rRNA gene fragments were cloned using a TOPO TA cloning kit (Invitrogen, Carlsbad, CA) following the manufacturer's instructions. Cloned inserts were screened by RFLP after amplification using the M13f and M13r primers (supplied with the TOPO cloning kit) using amplification conditions according to the manufacturer's instructions. The PCR products were digested with HaeIII and RsaI (Promega) in individual reactions and then pooled together. The resulting restriction fragments were separated by gel electrophoresis in $2.2 \%$ agarose gels and the gels were stained with ethidium bromide $\left(1 \mathrm{mg} \mathrm{L}^{-1}\right)$. 16S rRNA genes from representative clones of each RFLP group were partially sequenced (c. 900 bp) on an Applied Biosystems International PRISM
377 DNA sequencer using the M13f and M13r primers (Invitrogen). Sequences were compared with sequences in the GenBank database using BLASTN software (Altschul et al., 1997). All 16S rRNA gene sequences were also tested for chimeras in Chimera Check, version 2.7, Ribosomal Database project II (Cole et al., 2003). Chimeric 16S rRNA gene sequences that were detected within the data set were discarded. Cloned 16S rRNA gene sequences have been deposited in the EMBL nucleotide sequence database under the following accession numbers: AM489700-AM489706.

\section{Real-time (q) PCR}

PCR primers used for specific detection of the following dioxygenase gene fragments: phnAc (144 bp), nahAc (212 bp), pahAc (139bp), pdoA1 (358bp) and $x y l E$ (197bp), were designed using the software BEACON DESIGNER, v. 6.0 (Premier Biosoft, International, Palo Alto, CA) (Table 2). Positive controls: Burkholderia sp., Pseudomonas putida G7, P. putida OUS82 and Mycobacterium sp. (Table 3) (Johnsen et al., 2006, 2007) were a gift from Anders Johnsen, Department of Geochemistry, Geological Survey of Denmark and Greenland. The pUC19:xylE vector was a gift from Victor de Lorenzo, National Center for Biotechnology, Madrid, Spain. PCR reactions were individually optimized using diluted PCR products amplified from the control strains (Table 2).

Genes that gave a positive signal when amplified from environmental DNA ( $x y l E$ and $p h n A c$ ) were quantified by real-time qPCR. For this purpose, cleaned PCR products of $x y l E$ and $p h n A c$ genes were used as DNA standards. Clean PCR products for positive controls were obtained using the ExoSAP-IT kit (GE Healthcare) according to the manufacturer's instructions. The quality and concentration of PCR products were determined using an ND-1000 Spectrophotometer (Nanodrop Technologies, Wilmington, DE). qPCR was performed on a Light Cycler 2.0 instrument (LC, Roche). For each treatment, triplicate qPCR reactions were prepared from the bromodeoxyuridine-labeled DNA representing three separate sediment microcosms. A master mix

Table 2. PCR primers (constructed using software BEACON DESIGNER, v. 6.0), positive control strains and their corresponding dioxygenase genes

\begin{tabular}{lll}
\hline Primer pairs (5'-3') & Target gene and host (accession no, NCBI) & Sources \\
\hline Phn_fwd: ATATATCAGGACCAGACATTATTC & Partial phnAc dioxygenase gene, 144 bp, & Johnsen et al. (2006) \\
Phn_rev: GATGAGGTGATTGTGATGCG & Burkholderia sp., AF061751 & Johnsen et al. (2007) \\
Nah_fwd: GCAAATGACCTCCAAATACG & Partial nahAc naphthalene dioxygenase gene, & \\
Nah_rev: CCGAATGCCATCAACTCC & $212 \mathrm{bp}$, Pseudomonas putida G7, AB237655 & Johnsen et al. (2007) \\
Pah_fwd: AAAACTTGGGGGTGATG & Partial pahAc naphthalene dioxygenase gene, & Johnsen et al. (2007) \\
Pah_rev: TATTTGGAGGTCATTTGC & $139 \mathrm{bp}$, Pseudomonas putida OUS82, AB004059 & *de Lorenzo \\
Pdo_fwd: TCATTGCGAAGAAGACAG & Partial pdoA1 PAH ring-hydoxylating dioxygenase & \\
Pdo_rev: CCGTGAATAAAGGCTGAG & Gene, 358 bp, Mycobacterium sp., AJ494745 & \\
xylE_fwd: CAGCTGCGTGTACTGGACAT & pUC19::xylE vector, & \\
xylE_rev: AAGGTTGTGGATGAGGATG & Partial catechol-2,3-dioxygenase gene, 197 bp & \\
\hline
\end{tabular}

*The xylE vector was a gift from Victor de Lorenzo, National Center for Biotechnology, Madrid, Spain. 
Table 3. Relative abundances of TRFs and 16S rRNA gene clones amplified from bromodeoxyuridine-immunocaptured DNA extracted from phenanthrene-spiked sediment after 60 days incubation

\begin{tabular}{|c|c|c|c|c|}
\hline \multirow[b]{2}{*}{ TRF length bp (Hhal) } & \multirow[b]{2}{*}{ Closest match (NCBI) and accession number } & \multirow[b]{2}{*}{ Matching isolate* and accession number } & \multicolumn{2}{|c|}{ Relative abundance (\%) } \\
\hline & & & $\mathrm{TRF}^{\dagger}$ & Clone \\
\hline \multirow[t]{2}{*}{60} & Exiguobacterium oxidotolerans & Exiguobacterium sp. AE3 & 5.9 & 7.3 \\
\hline & $99 \%$ sequence similarity to $A Y 489701 \S$ & 99\% sequence similarity to EF530574 & & \\
\hline \multirow[t]{2}{*}{76} & Schewanella baltica & & 31.1 & 34.3 \\
\hline & 99\% sequence similarity to AJ000214 & & & \\
\hline \multirow[t]{2}{*}{79} & Methylomonas methanica & & 30.3 & 24.3 \\
\hline & $100 \%$ sequence similarity to AF150806 & & & \\
\hline \multirow[t]{2}{*}{97} & Deltaproteobacterium & & 8.7 & 11.4 \\
\hline & 99\% sequence similarity to DQ079636 & & & \\
\hline \multirow[t]{2}{*}{101} & Bacteroidetes bacterium & & 9.4 & 12.8 \\
\hline & $98 \%$ sequence similarity to $\mathrm{DQ} 185611$ & & & \\
\hline 128 & Unidentified bacterium & & 5.0 & $x$ \\
\hline \multirow[t]{2}{*}{205} & Unclassified Gammaproteobacterium, & Pseudomonas sp. AE2 & 1.8 & 2.8 \\
\hline & $100 \%$ sequence similarity to $\mathrm{AM} 167991^{\S}$ & 98\% sequence similarity to EF528261 & & \\
\hline \multirow[t]{2}{*}{218} & Pseudomonas sp. & Pseudomonas sp. AE1 & .8 & 7.1 \\
\hline & $99 \%$ sequence similarity to $\mathrm{AM} 167976^{\S}$ & 97\% sequence similarity to EF528260 & & \\
\hline
\end{tabular}

\footnotetext{
*Strain designations given to isolates based on closest matches to their full-length $16 \mathrm{~S}$ rRNA gene sequences.

${ }^{\dagger}$ Data represent the average relative abundance values of TRFs from three replicate sediment microcosms.

${ }^{\ddagger} 16 \mathrm{~S}$ rRNA gene sequences were digested in silico using the recognition site for restriction enzyme Hhal.

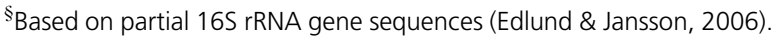

$X, 16 S$ rRNA gene sequence not obtained in clone library.
}

containing $3 \mathrm{mM} \mathrm{MgCl} 2,0.5 \mu \mathrm{M}$ of each primer and $1 \mu \mathrm{L}$ bovine serum albumin (BSA; $1 \mathrm{mg} \mathrm{mL}^{-1}$ ) was prepared on ice and added to a Platinum ${ }^{\circledR}$ SYBR $^{\circledR}$ Green qPCR SuperMix-UGD kit (Invitrogen). Eighteen microliters of master mix were combined with $2 \mu \mathrm{L}$ of serially diluted template in capillaries, which were sealed and placed in the LightCycler. The following temperature profile was used for qPCR: after initial uracil DNA glycosylase (UGD) incubation at $50{ }^{\circ} \mathrm{C}$ for $120 \mathrm{~s}$ and at $95^{\circ} \mathrm{C}$ for $120 \mathrm{~s}$, amplification was carried out for 45 cycles with denaturation at $94^{\circ} \mathrm{C}$ for $5 \mathrm{~s}$, annealing at $60{ }^{\circ} \mathrm{C}$ for $5 \mathrm{~s}$ and extension at $72^{\circ} \mathrm{C}$ for $8 \mathrm{~s}$. The temperature transition rate was $20^{\circ} \mathrm{Cs}^{-1}$. Melting curve analysis was conducted in one cycle with three segments: $95^{\circ} \mathrm{C}$ for $60 \mathrm{~s}$, $60{ }^{\circ} \mathrm{C}$ for $15 \mathrm{~s}$ and then increased to $95^{\circ} \mathrm{C}$. The temperature transition rate was $20^{\circ} \mathrm{Cs}^{-1}$ for the first and second segments and $0.1{ }^{\circ} \mathrm{C}$ for the third segment. Fluorescence measurements were taken during the final temperature ramp. Melting curves were routinely checked to confirm quantification of the desired product. To confirm that the correct genes were amplified from environmental DNA, direct sequencing of $\mathrm{qPCR}$ products was performed with qPCR primers (Table 2).

The numbers of gene copies in the positive controls were calculated from the formula developed previously by Whelan et al. (2003).

DNA $($ copy $)=\frac{6.02 \times 102^{3}(\text { copy } / \mathrm{mol}) \times \text { DNA amount }(\mathrm{g})}{\text { DNA length }(\mathrm{dp}) \times\left(660\left(\mathrm{~g} \mathrm{~mol}^{-1} \mathrm{dp}^{-1}\right)\right.}$
DNA concentration was determined using an ND-1000 Spectrophotometer and this value was then inserted into the formula above to calculate the numbers of copies for each gene. The threshold cycle $\left(C_{\mathrm{t}}\right)$ values for each replicate dilution were measured to generate standard curves. The $C_{\mathrm{t}}$ value for each standard was plotted against the $\log _{10}$ of the starting DNA quantity to generate a standard curve. The standard curve for $x y l E$ ranged from $1 \times 10^{3}$ to $1 \times 10^{7}$ gene copies and the standard curve for phnAc ranged from $1 \times 10^{3}$ to $1 \times 10^{9}$ gene copies. The resulting straightline equations that were used for calculations of copies were $C_{\mathrm{t}}=-3.03 \times \log _{10}$ (copy number) +44.49 and $C_{\mathrm{t}}=$ $-3.06 \times \log _{10}$ (copy number) +35.95 for $x y l E$ and $p h n A c$, respectively. The $p h n A c$ and $x y l E$ genes that were amplified and sequenced from the sediments were deposited in the NCBI nucleotide sequence database under the following accession numbers: EU251476 and EU251477, respectively.

\section{Phenanthrene degradation by isolates}

Three bacterial strains that were previously isolated from the polluted Baltic Sea sediments after 7 days of incubation in phenanthrene-spiked microcosms (Edlund \& Jansson, 2006) were assigned to the genus level based on their 16S rRNA gene sequences and given candidate strain numbers (Table 3 ). The full-length $16 \mathrm{~S}$ rRNA gene sequences for the isolates were deposited in GenBank under the following accession numbers: EF528260, EF528261 and EF530574. 
The isolates were tested for their ability to grow on and degrade phenanthrene in liquid cultures. Phenanthrene concentrations in the cultures were monitored using GCMS as described above. Degradation experiments were performed in sediment extract medium to mimic nutrient conditions typical of the area of isolation. Sediment extract medium was prepared by filtering Baltic Sea surface sediments through $0.2-\mu \mathrm{m}$ filters (Sarstedt, Nümbrecht, Germany) and collecting the water fraction. The cells were pregrown in 10\% tryptic soy broth medium (Difco Laboratories, Detroit, MI), collected by centrifugation (10 min, $970 \mathrm{~g}$ ), washed once with sterile water and resuspended in $100 \mathrm{~mL}$ sediment extract medium containing $10 \mu \mathrm{g}$ phenanthrene $\mathrm{mL}^{-1}$ to $c .5 \times 10^{7} \mathrm{CFU} \mathrm{mL}^{-1}$ sediment medium in $500-\mathrm{mL}$ glass flasks. Subsequent $\mathrm{OD}_{600 \mathrm{~nm}}$ values were diluted to 0.12 for all bacterial strains to ensure that all cultures started with approximately the same amount of cells. The cultures were incubated in the dark at $5{ }^{\circ} \mathrm{C}$ with shaking (150 r.p.m.) and triplicate cultures were established for each isolate. Uninoculated controls containing only phenanthrene-spiked sediment extract medium were also established in triplicate. Flasks were covered with parafilm and wrapped in an aluminum foil to avoid evaporation of phenanthrene and exposure to light. Cell growth was monitored by enumeration of CFU on $10 \%$ tryptic soy broth agar plates, incubated in the dark at $5{ }^{\circ} \mathrm{C}$.

\section{Screening isolates for degradation genes}

Selected bacterial isolates were screened by PCR for the presence of $p h n A c$ and $x y l E$ genes using the same primer pairs as those used for qPCR of DNA directly extracted from sediment (Table 2). PCR conditions were as described previously (Edlund et al., 2006) with the following modifications: each step in a cycle was $40 \mathrm{~s}$, annealing temperature was $60^{\circ} \mathrm{C}$ and 35 cycles of amplification were performed. The amplified DNA was verified by gel electrophoresis of PCR products in $2.2 \%$ agarose gels (containing 2.2\% ethidium bromide). To determine sequence identities, the PCR products were cloned and sequenced as described above. The phnAc genes were deposited in the EMBL nucleotide sequence database under the following accession numbers: AM491127-AM491129.

\section{Results}

\section{Phenanthrene transformation in sediment microcosms}

Phenanthrene levels in phenanthrene-spiked sediment slurries were significantly reduced after 60 days of incubation. The sediments that were spiked with $10 \mu \mathrm{g} \mathrm{mL}^{-1}$ phenanthrene (treatments 3,4 and 5, Table 1) contained on average
$3.7 \mu \mathrm{g} \mathrm{mL}^{-1}$ phenanthrene on initial sampling dates, suggesting that a substantial part of the phenanthrene was immediately absorbed to the flasks, parafilm and/or sediment particles. However, after 60 days, the phenanthrene concentration had decreased to $0.8 \mu \mathrm{g} \mathrm{mL} L^{-1}$, suggesting that microorganisms in the sediment might be degrading the compound.

\section{Actively growing bacterial community profiles and bacterial identification}

Bromodeoxyuridine-immunocapture was used to selectively extract DNA corresponding to actively growing bacterial populations in the sediments enriched with phenanthrene. To ensure that sufficient bromodeoxyuridine was available throughout the 60-day incubation period, bromodeoxyuridine was added repeatedly to some treatments and compared with treatments where bromodeoxyuridine was only added at the beginning of the experiment. The bacterial community structure of the bromodeoxyuridine-immunocaptured DNA was profiled by T-RFLP and the resulting TRFs were compared between treatments.

When bromodeoxyuridine was added three times during the first week of incubation (treatment 4, Fig. 1), there was a decrease in the number of TRFs detected at days 2 and 7 , compared with treatments with only one addition (treatment 2, Fig. 1), suggesting that some bacteria may either have been inhibited or may have been favored by the increased bromodeoxyuridine concentration and grew to the expense of other populations (e.g. those represented by TRFs 101 and 218). However, after 2 months of incubation, the community with repeated bromodeoxyuridine additions (treatment 4, Fig. 1) resembled that where bromodeoxyuridine was added only at day 0 (treatment 3 , Fig. 1). In the microcosms where bromodeoxyuridine was added at day 58 (2 days before the last sampling; treatment 5, Fig. 1), two novel TRFs appeared at 338 and $369 \mathrm{bp}$, indicating that these bacterial populations had sufficiently high growth rates to incorporate bromodeoxyuridine. Their appearance may also imply that new niches were available at the end of the incubation period.

The numbers and relative abundances of TRFs from the T-RFLP data were used to determine the impact of the different incubation conditions on the diversity of the actively growing members of the bacterial community in the sediments. In addition, the total dominant bacterial members of the community were monitored during the incubation period (treatment 1). There was a significant decrease in the phylotype diversity of the total community after 60 days of incubation, from $c .40$ initial TRFs $\left(H^{\prime}: 3.2\right.$; E: 0.9$)$ to 10 TRFs ( $\left.H^{\prime}: 1.7 ; E: 0.5\right)$ (Fig. 1, treatment 1$)$. The numbers of TRFs in the bromodeoxyuridine-immunocaptured DNA representing the active community were relatively similar over the entire incubation period in the 


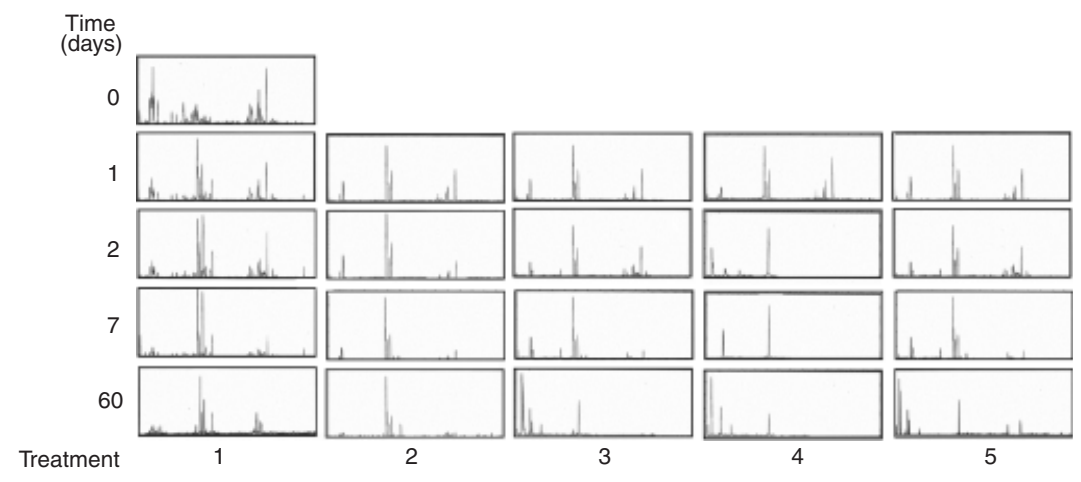

Fig. 1. Representative electropherograms from TRF analysis (T-RFLP) of $16 \mathrm{~S}$ rRNA gene fragments amplified from total DNA extracts (treatment 1) and from bromodeoxyuridine-labeled DNA (treatments 2-5) representing sediment microcosm treatments (see Table 1 for a more detailed description of treatments). 16S rRNA gene community profiles from total DNA extracts were analyzed at all sampling dates, including day 0 (before incubation started), and all other profiles were analyzed at days $1,2,7$ and 60 of incubation. The $x$-axis in each individual electropherogram represents TRF sizes with a minimum of 60 and a maximum of $500 \mathrm{bp}$ in each case. The $y$-axis represents fluorescence intensity and the maximum values varied between samples. For the sake of comparison, the $y$-axis of the electropherograms was adjusted so that the abundant peaks could all be visualized within the same area. The SD for mean relative abundance values (\%) of TRFs from three replicate sediment microcosms ranged from SD: \pm 0.9 to $1.6 \%$.

phenanthrene-spiked microcosms, with $c .10$ TRFs (2 days: $H^{\prime}: 1.7$ and $E: 0.7 ; 2$ months: $H^{\prime}: 1.5$ and $\left.E: 0.6\right)$. However, in the unspiked microcosms without added phenanthrene, the numbers of TRFs from actively growing bacteria decreased from 10 to 6 and the diversity decreased from an $H^{\prime}$ of 1.7 to 1.0 after 60 days of incubation (Fig. 1).

A clear shift in the T-RFLP profiles of the actively growing bacterial community was observed in sediments that were spiked with phenanthrene after 60 days of incubation compared with the TRFs in unspiked microcosms (Fig. 1). Several TRFs (e.g. TRFs 60, 76, 79, 97 and 128 bp) increased in relative abundance in phenanthrene-spiked sediments, suggesting that they were positively influenced by phenanthrene addition. By contrast, some of the TRFs detected in the control microcosms without phenanthrene (TRFs 210, 213 and $242 \mathrm{bp}$ ) had a higher relative abundance compared with the microcosms spiked with phenanthrene. This suggests that the corresponding populations were negatively impacted when phenanthrene was added or that phenanthrene had a below-average positive effect on these populations. However, some TRFs (e.g. 201, 205 and 218 bp) were dominant in both phenanthrene-spiked and -unspiked microcosms, indicating that the corresponding populations were neither effected positively nor negatively by addition of phenanthrene.

Bacteria that were growing and possibly enriched in the phenanthrene-spiked sediments were further identified by cloning and sequencing of $16 \mathrm{~S}$ rRNA genes amplified from bromodeoxyuridine-immunocaptured DNA (treatment 3) in order to match sequence identities to specific TRFs. A subset of 70 clones (out of $c .2000$ total) was screened by RFLP using HhaI and RsaI. Seven unique restriction patterns were obtained, indicating a low diversity of metaboli- cally active community members in polluted Baltic Sea sediments, similar to the results of a previous study of sediments collected in the same sampling area (Edlund \& Jansson, 2006). All of the clones could be matched to specific TRFs in the T-RFLP profiles (Table 3). This enabled us to estimate the relative abundances of the corresponding populations in the sediment community. Both the T-RFLP and the cloning approaches resulted in similar relative abundance values (Table 3), confirming the validity of these molecular tools.

Populations with $16 \mathrm{~S}$ rRNA gene sequences corresponding to Schewanella baltica (TRF 76) and Methylomonas methanica (TRF 79) were the most dominant metabolically active populations (each c. $30 \%$ relative abundance), using both approaches (Table 3 ). These bacteria were only identified in the phenanthrene-spiked microcosms, in addition to Exiguobacterium oxidotolerans (TRF 60) and an unidentified bacterium (TRF 128) (Tables 3 and 4). Therefore, it is likely that bacteria representative of $S$. baltica, M. methanica, E. oxidotolerans and the unidentified bacterium played a role in phenanthrene degradation or at least were stimulated to grow in its presence.

A Pseudomonas sp. (TRF 218) was present in all samples, including those to which bromodeoxyuridine had not been added, suggesting that it was dominant and metabolically active irrespective of the incubation conditions tested (Tables 3 and 4). TRFs 97, 101 and 205, corresponding to an uncultured Deltaproteobacterium, a Bacteroidetes sp. and a Pseudomonas strain, respectively, were also abundant and metabolically active irrespective of phenanthrene addition (Table 4).

TRFs 101 and 205, corresponding to the Bacteroidetes sp. and the Pseudomonas sp. mentioned above, were not present 
Table 4. Representative TRFs present in community profiles from total DNA extracts and in bromodeoxyuridine-immunocaptured DNA after 60 days of incubation in sediment microcosms

\begin{tabular}{|c|c|c|c|c|c|}
\hline \multirow[b]{2}{*}{ TRF (bp) treatment* } & \multirow{2}{*}{$\frac{\text { Total DNA }}{1}$} & \multicolumn{4}{|c|}{ Bromodeoxyuridine-labeled DNA } \\
\hline & & 2 & 3 & 4 & 5 \\
\hline 60 & - & - & + & + & + \\
\hline 76 & - & - & + & + & + \\
\hline 79 & - & - & + & + & + \\
\hline 97 & + & - & + & + & + \\
\hline 101 & + & + & + & - & \\
\hline \multicolumn{6}{|l|}{-} \\
\hline 128 & - & - & + & + & + \\
\hline 205 & + & + & + & - & \\
\hline \multicolumn{6}{|l|}{-} \\
\hline 218 & + & + & + & + & + \\
\hline
\end{tabular}

\pm , TRF present/not present in community profiles from triplicate sediment microcosms.

*See Table 1 for description of treatments.

in treatment 4 , where bromodeoxyuridine was added several times, suggesting that they were inhibited by high levels of bromodeoxyuridine addition or outcompeted by other more fast-growing bacteria (Table 4).

\section{Quantification of dioxygenase genes in actively growing bacteria}

Gene copies of the $x y l E$ and $p h n A c$ genes encoding catechol2,3-dioxygenase and the iron-sulfur protein (large) subunit of PAH dioxygenase, respectively, were monitored in bromodeoxyuridine-immunocaptured DNA by real-time PCR over the sampling period. None of the other functional genes tested (Table 2) were detected in any samples. In the phenanthrene-spiked sediments, $x y l E$ gene copy numbers increased from c. 40000 copies $\mathrm{mL}^{-1}$ sediment on day 1 to c. 260000 copies $\mathrm{mL}^{-1}$ sediment on day 7 (Fig. 2). Between days 7 and 60, the gene copy numbers decreased to approximately original levels at 45000 copies $\mathrm{mL}^{-1}$ sediment. There was also an increase in the number of $x y l E$ gene copies in the unspiked microcosms containing background levels of phenanthrene from $c .25000$ copies $\mathrm{mL}^{-1}$ sediment on day 1 to $c .82000$ on day 7 , followed by a decrease to c. 30000 copies $\mathrm{mL}^{-1}$ sediment by the 60 -day sampling date. The phnAc genes were considerably more abundant in the phenanthrene-enriched sediments, with copy numbers that increased from $c .1 .5 \times 10^{5}$ copies $\mathrm{mL}^{-1}$ sediment on day 1 , to $c .3 \times 10^{6}$ copies $\mathrm{mL}^{-1}$ sediment on day 7 , followed by a decrease to $c .3 .7 \times 10^{4}$ copies $\mathrm{mL}^{-1}$ sediment after 2 months of incubation (Fig. 2). By contrast, in the sediments without added phenanthrene phnAc gene copy numbers remained relatively low and stable, ranging from 2500 to 5000 copies $\mathrm{mL}^{-1}$ throughout the incubation period.
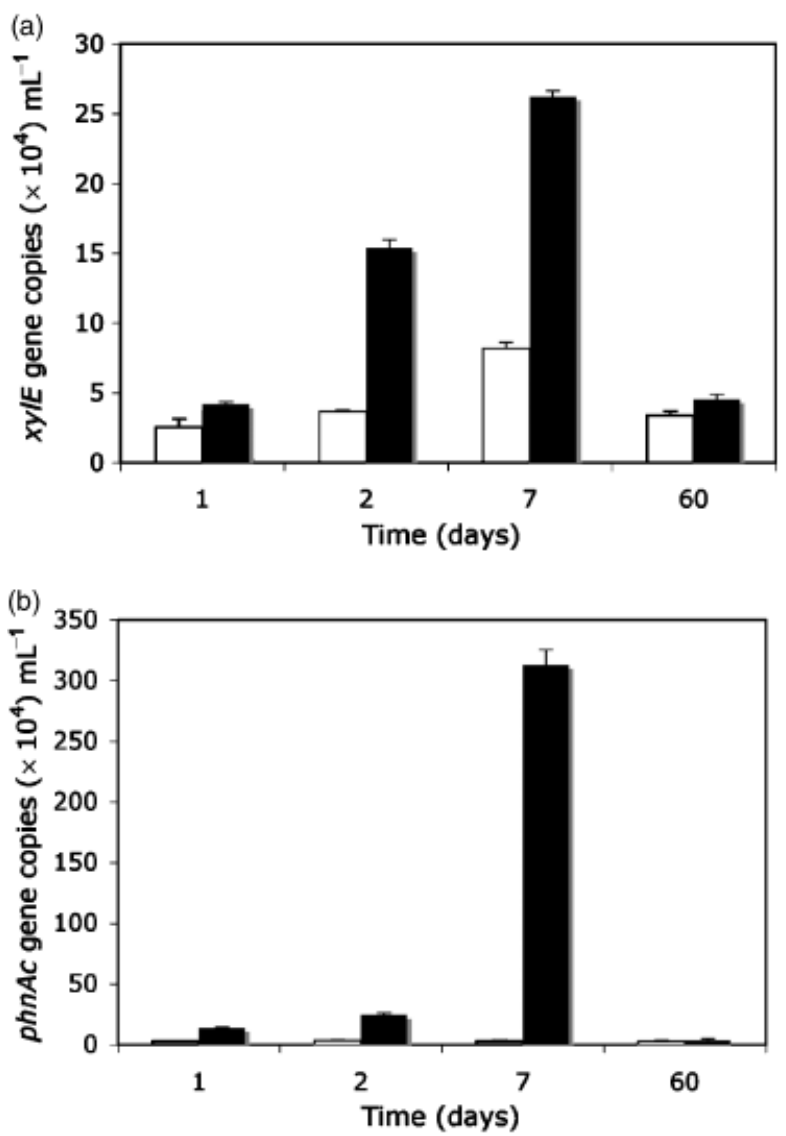

Fig. 2. Quantification of dioxygenase genes xylE (a) and phnAc (b) in phenanthrene-enriched sediment (black bars) and unspiked sediment (white bars) during 60 days of incubation (treatments 2 and 3, Table 1, respectively). The data represent the average of triplicate sediment microcosms and the error bars represents the SD of the mean.

\section{Characterization of isolates}

Three of the 16S rRNA gene sequences that were identified as representative of abundant and active bacteria in the bromodeoxyuridine-extracted DNA from the sediment microcosms were closely related (97-99\%) to isolates that were obtained previously from the same sediments (Table 3 ). These isolates had 16S rRNA gene sequences that were related to $16 \mathrm{~S}$ rRNA gene sequences of a pseudomonad (TRF 218; i.e. one of those that was abundant and active in all samples, Table 4), another pseudomonad (TRF 205; i.e. abundant and active irrespective of phenanthrene addition, but inhibited by repeated doses of bromodeoxyuridine, Table 4) and E. oxidotolerans (TRF 60; abundant and active in the presence of phenanthrene, Table 4). Based on their full-length $16 \mathrm{~S}$ rRNA gene sequences, we provided each of the isolates with a strain designation as follows: pseudomonad corresponding to TRF 218: Pseudomonas sp. AE1 pseudomonad corresponding to TRF 205: Pseudomonas sp. 

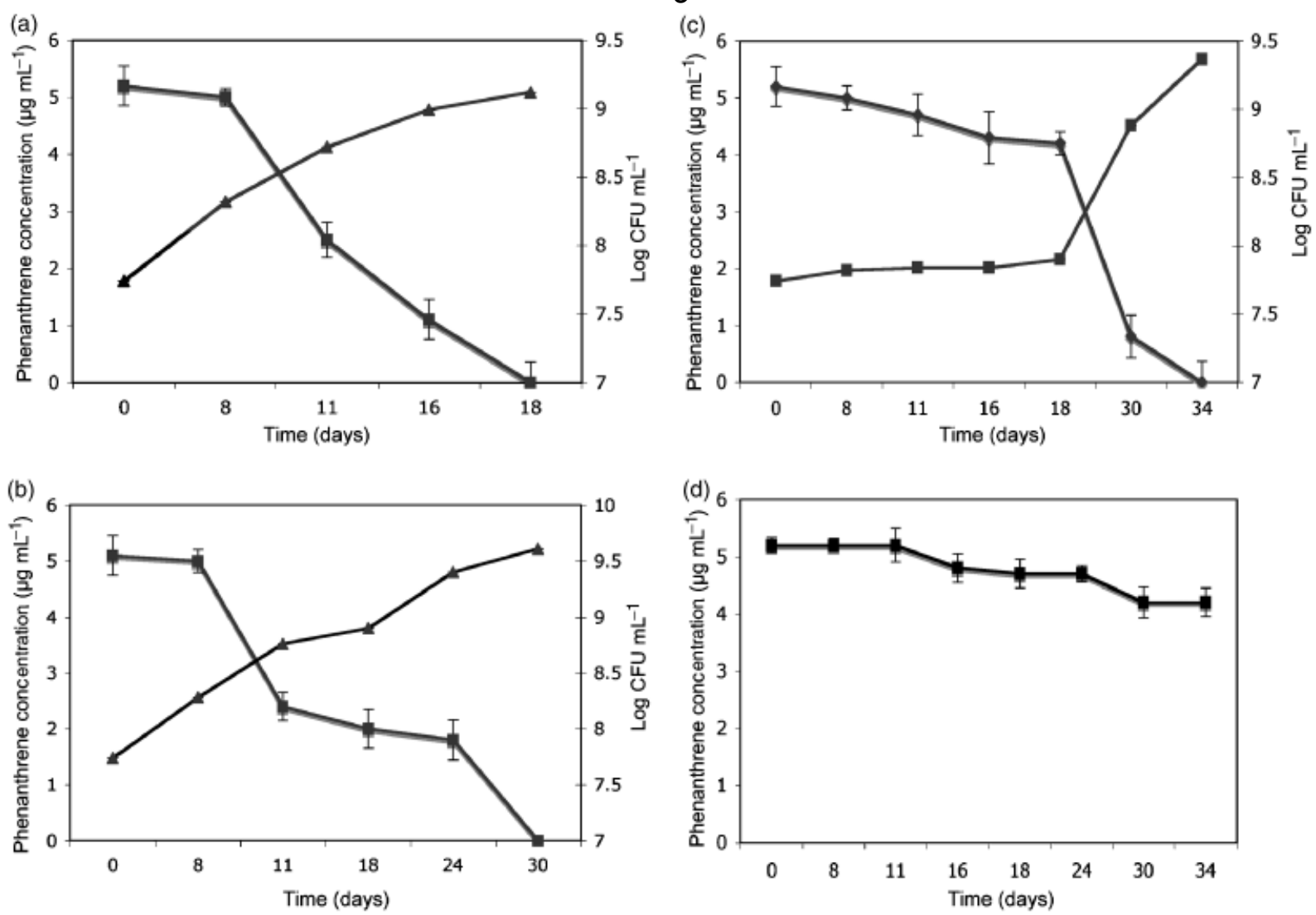

Fig. 3. Phenanthrene degradation $(\mathbf{\square})$ and $\log \mathrm{CFU}(\mathbf{\bullet})$ in sediment extract medium spiked with $10 \mu \mathrm{g}$ phenanthrene $\mathrm{mL}^{-1}$. (a) Exiguobacterium sp. AE3, (b) Pseudomonas sp. AE1, (c) Pseudomonas sp. AE2 and (d) uninoculated control. Error bars represent the SD of the mean of triplicate cultures. The error bars for the growth curves are within the area of the data points.

AE2, and Exiguobacterium species corresponding to TRF 60: Exiguobacterium sp. AE3 (Table 3).

The isolates were tested for their ability to degrade phenanthrene and were also screened for the presence of dioxygenase genes that could express enzymes functioning in phenanthrene degradation. Phenanthrene levels were reduced to background levels in sediment extract medium incubated with all three bacterial cultures, compared with negligible reduction of the compound in uninoculated controls (Fig. 3). The rates of phenanthrene removal were different for the different bacterial cultures. Exiguobacterium sp. AE3 reduced phenanthrene to background levels after 18 days of incubation, whereas cultures of the two pseudomonads, Pseudomonas sp. AE1 and Pseudomonas sp. AE2, depleted phenanthrene after 30 and 34 days, respectively (Fig. 3). The numbers of CFUs increased for all of the tested bacteria during the incubation period, suggesting that they used phenanthrene as a carbon source. All isolates carried an identical phnAc gene (99\% sequence similarity to AF061751, $\mathrm{NCBI}$ ) but none of them harbored $x y l E$ genes. This suggests that the phnAc dioxygenase enzyme was used for phenanthrene degradation by the isolates. Moreover, the 144-bp long phnAc gene fragments that were sequenced from isolates and sediments were $100 \%$ identical when multiple sequence alignment was performed with the MUSCLE software, version 3.5, available at http://drive5.com/muscle (Edgar, 2004).

\section{Discussion}

Molecular approaches, such as those applied in this study, are useful for identification of metabolically active bacteria, including not yet described species (i.e. not yet cultured) that may play significant roles in pollutant degradation or in other community processes (Nogales et al., 1999). Specifically, we identified bacterial populations that grew in Baltic Sea sediments that were spiked with phenanthrene and incubated for 60 days. The incubation conditions were cold $\left(5^{\circ} \mathrm{C}\right)$ and the community was exposed to oxygen during sampling and incubation, thereby also selecting for populations that were both psychrotolerant and oxygen tolerant. The combination of T-RFLP, qPCR, cloning and sequencing of bromodeoxyuridine-labeled DNA enabled the composition of the dominant and active members of the sediment 
bacterial community to be identified in parallel with identification and quantification of PAH degradation genes that were present during the enrichment process.

The source of material in this study was sediment that had been collected previously from a polluted site in the Baltic Sea subsequent to remediation by dredging (Edlund et al., 2006) and it was stored frozen before setup of the phenanthrene enrichments. Although it was not possible to resample the original site to obtain fresh polluted sediments, because these had been removed during the dredging process, the frozen sediment did contain pollutants and populations representative of the original sampling site. We are aware that some microorganisms originally present in the sediment might have died during sampling and storage. However, it was encouraging to find that several of the $16 \mathrm{~S}$ rRNA gene sequences representative of growing populations that were detected initially were still detected as growing members of the community in the present study.

Some of the $16 \mathrm{~S}$ rRNA gene sequences that we detected in the phenanthrene-spiked microcosms were related to isolates obtained previously from the same PAH-contaminated Baltic Sea sediments (Edlund \& Jansson, 2006). In this study, we found that three of the isolates, given the strain designations Exiguobacterium sp. AE3, Pseudomonas sp. AE1 and Pseudomonas sp. AE2, were capable of growth on and degradation of phenanthrene. Although Exiguobacterium is a relatively unstudied genus, a couple of strains that derive from extreme environments have been described previously (Collins et al., 1983; Vishnivetskaya et al., 2000). These strains have shown interesting features such as high survival during long-term freezing, rapid growth at low temperatures and a high osmotic tolerance (Collins et al., 1983; Vishnivetskaya et al., 2000; Isao et al., 2004), similar to the conditions of the sediments used in our study. In addition, pseudomonads related to the Pseudomonas isolates in our study, Pseudomonas fluorescens and Pseudomonas migulae, were isolated previously from phenanthrene-polluted environments and these had a high capacity for phenanthrene degradation (Sanseverino et al., 1993; Muñoz et al., 2003).

Although one might expect anaerobic bacterial populations to carry out degradation functions in the largely anaerobic sediments in situ, aerobic degrading isolates and aerobic PAH degradation genes were found. Therefore, the question remains as to whether these populations play a key role in bioremediation of Baltic Sea sediments. We know from recent studies of a relatively clean area of the Baltic Sea that the microbial community structure varies at different vertical layers in the sediment and this is correlated to redox potential, with the upper sediment layers being oxic (Edlund et al., 2008). In the present investigation, we collected surface sediments, including the upper presumably oxic layers, and this could be the source of our isolates and aerobic degradation genes that were subsequently enriched.
Other studies have also reported high numbers of aerobic aromatic degrading organisms and genes in apparent anaerobic aquifers (Hendrickx et al., 2005; Fahy et al., 2006). Therefore, the relative contributions of aerobic and anaerobic processes in these environments remain to be elucidated.

All of our phenanthrene-degrading isolates harbored the phnAc gene, which is involved in the initial hydroxylation step of phenathrene degradation (Lauri \& Lloyd-Jones, 1999). These results are in line with a previous study where enrichment of the phn genotype was observed in isolates from phenanthrene-amended PAH-contaminated soils from a broad geographical distribution (central Siberia, Antarctica, Ross Island and New Zealand) (Lauri \& Lloyd-Jones, 2000).

In contrast to the isolates that only contained the phnAc gene, both $x y l E$ and $p h n A c$ genes were detected by qPCR of bromodeoxyuridine-labeled DNA extracted from the sediment (Fig. 2). Both genotypes were found to increase significantly after 7 days of incubation with phenanthrene. The $x y l E$ gene (EC 1.13.11.2 in Kyoto Encyklopedia of Genes and Genomes, KEGG available at http://www.genome.jp/ $\mathrm{kegg} /$ ) expresses meta cleavage of catechol in the lower pathways of PAH degradation. In line with our results, another study of PAH-contaminated soil showed that $x y l E$ was significantly expressed during phenanthrene degradation (Cunliffe et al., 2006). However, we found a greater increase in expression levels of $p h n A c$ than of $x y l E$. This difference may reflect that phnAc is critical for initial degradation of phenanthrene and that the dioxygenase encoded by $x y l E$ is one of several options for further degradation of the compound. The decrease in $x y l E$ and phnAc gene copy numbers at the end of the experiment may reflect the corresponding decrease in levels of phenanthrene. Moreover, all phnAc gene fragments that were sequenced from isolates and sediments were identical, indicating that this gene may have been recently transferred between members of the bacterial community. These results are in line with a previous study where highly conserved $p h n$ genes were shared by groups of taxonomically diverse hosts in naphthalene-contaminated seep sediments (Wilson et al., 2003). However, we only analyzed $144 \mathrm{bp}$ within the complete PAH-catabolic gene cluster that encompasses $11451 \mathrm{bp}$ in total (Lauri \& Lloyd-Jones, 1999) and we do not know whether the remaining genes were present. Also, there could be other catabolic pathways involved in phenanthrene detection that we did not screen for, such as the phd genes described for phanthrene degradation in river sediments (Goyal \& Zylstra, 1996, 1997).

Our results indicated that Exiguobacterium sp. AE3 only grew in the microcosm experiments when phenanthrene was added. By contrast, the two pseudomonads, Pseudomonas sp. AE1 and Pseudomonas sp. AE2, were abundant and growing in the sediment microcosms in the presence and 
absence of phenanthrene, suggesting that they could also utilize endogenous carbon sources for growth and that their growth might be independent of phenanthrene levels in situ. Previous studies applied stable isotope probing (SIP) to specifically study metabolically active phenanthrenedegrading bacteria in PAH-contaminated soil (Singleton et al., 2005, 2006). In those studies, community members belonging to the genus Pseudomonas were responsible for pyrene degradation while some Acidovorax representatives were responsible for phenanthrene degradation. Taken together, these studies suggest that phenanthrene-degradation abilities are not species specific but that they are dependent on the local conditions and the genetic makeup of the indigenous bacterial flora.

In addition to the isolates mentioned above, bacteria related to M. methanica and S. baltica (Table 4) were found to be abundant and metabolically active in the phenanthrene-spiked sediments using the bromodeoxyuridine immunocapture approach, but we did not have isolates representative of these bacteria. The molecular data, however, provide a clue that these bacteria are interesting as potential phenanthrene degraders and they present target populations for specific isolation using selective cultivation conditions in the future. It is also possible that these bacteria use metabolites or excreted products from the phenanthrene-degrading community members for growth. In previous studies, it was shown that Schewanella putrefaciens, which is a close relative to $S$. baltica, has the potential to perform reductive dechlorination of carbon tetrachloride and some components of oil (Backhus et al., 1997; MartínGil et al., 2004) and is capable of growing both aerobically and anaerobically at the expense of many different electron acceptors (Nealson et al., 1995; Kostka et al., 1996). The roles of the Methylomonas and Schewanella species in this study remain unknown. However, their presence in the spiked microcosms suggests that they may be involved in phenanthrene degradation but this hypothesis remains to be confirmed by a study of corresponding isolates.

After 2 months of incubation, the total community richness based on T-RFLP of directly extracted DNA decreased in all treatments by c. $75 \%$ (Fig. 1), which may be due to a 'bottle effect' (i.e. some bacterial populations were favored by the specific incubation conditions used and increased in growth while the growth of other populations was repressed, Pritchard et al., 1979). In contrast to the totally extracted DNA, a decrease in the number of TRFs was not observed for $16 \mathrm{~S}$ rRNA genes that were amplified from bromodeoxyuridine-labeled DNA, which would be expected if the incubation conditions alone were acting on the community. We previously found a low diversity of metabolically active bacteria in Baltic Sea sediments (Edlund \& Jansson, 2006) and in soil (Hjort et al., 2007) using the same approach. Therefore, these results suggest that only a small fraction of the total bacterial community is active at any particular time, depending on the specific environmental conditions. However, it should be kept in mind that additional rare bacterial species that are below the detection limit of our method may also play important ecological roles.

In summary, we used a combination of approaches, to identify psychrotolerant bacteria and functional genes that were selectively enriched in the presence of phenanthrene. Some bacterial isolates, including a novel Exiguobacterium strain, were represented as growing members of the sediment community in the phenanthrene enrichments using molecular approaches and they could grow on and degrade phenanthrene at $5{ }^{\circ} \mathrm{C}$. Therefore, these strains represent populations that are active in polluted Baltic Sea sediments and potential contributors to PAH transformations in oxic layers of the sediments in situ.

\section{Acknowledgements}

We thank Anders R. Johnsen, Department of Geochemistry, Geological Survey of Denmark and Greenland, and Victor de Lorenzo, National Center for Biotechnology, Madrid, Spain, for supplying us with control bacterial strains for qPCR analysis; Elisabet Börjesson and Leticia Pizzul, Department of Microbiology, Swedish University of Agricultural Sciences, Uppsala, Sweden, and Tord Eriksson, Södertörn University college for assistance with GC-MS analyses and contribution towards cultivation of phenanthrene-transforming bacteria; and Sonja Löfmark and Benjamin Edvinsson, Department of Laboratory Medicine, Karolinska Institute, Sweden, for help with qPCR analysis and access to their equipment. We also thank Sara Sjöling, Södertörn University College, Huddinge, Sweden, and an anonymous reviewer for critically reviewing the manuscript. The study was funded by the Baltic Sea Foundation and in part by US Department of Energy Contract DE-AC0205CH11231 with Lawrence Berkeley National Laboratory.

\section{References}

Altschul SF, Madden TL, Schaeffer AA, Zhang J, Zhang Z, Miller W \& Lipman DJ (1997) Gapped BLAST and PSI-BLAST: a new generation of protein database search programs. Nucleic Acids Res 25: 3389-3402.

Artursson V \& Jansson JK (2003) Use of bromodeoxyuridine immunocapture to identify bacteria associated with arbuscular mycorrhizal hyphae. Appl Environ Microbiol 69: 6208-6215.

Backhus DA, Picardal FW, Johnson S, Knowles T, Collins R, Radue A \& Sanggoo K (1997) Soil- and surfactant-enhanced reductive dechlorination of carbon tetrachloride in the presence of Shewanella putrefaciens 200. J Contam Hydrol 28: 337-361. 
Brinch UC, Ekelund F \& Jacobsen CS (2002) Method for spiking soil samples with organic compounds. Appl Environ Microbiol 68: $1808-1816$.

Cole JR, Chai B, Farris RJ, Wang Q, Kulam SA \& McGarrell DM (2003) The Ribosomal Database Project (RDP-II): previewing a new autoaligner that allows regular updates and the new prokaryotic taxonomy. Nucleic Acids Res 31: 442-443.

Collins MD, Lund BM, Farrow JAE \& Schleifer KH (1983) Chemotaxonomic study of an alkalophilic bacterium, Exiguobacterium aurantiacum gen. nov., sp. nov. J Gen Microbiol 129: 2037-2042.

Cunliffe M, Kawasaki A, Fellows E \& Kertesz MA (2006) Effect of inoculum pretreatment on survival, activity and catabolic gene expression of Sphingobium yanoikuyae B1 in aged polycyclic aromatic hydrocarbon-contaminated soil. FEMS Microbiol Ecol 58: 364-372.

Edgar RC (2004) MUSCLE: multiple sequence alignment with high accuracy and high throughput. Nucleic Acids Res 32: 1792-1797.

Edlund A \& Jansson JK (2006) Changes in dominant and active bacterial communities before and after dredging of highly polluted Baltic Sea sediments. Appl Environ Microbiol 72: 6800-6807.

Edlund A, Soule T, Sjöling S \& Jansson JK (2006) Microbial community structure in polluted Baltic Sea sediments. Environ Microbiol 8: 223-232.

Edlund A, Hårdeman F, Jansson JK \& Sjöling S (2008) Active bacterial community structure along vertical redox gradients in Baltic Sea sediment. Environ Microbiol, DOI: 10.1111/ j.1462-2920.2008.01624.x.

Fahy A, McGenity TJ, Timmis KN \& Ball AS (2006)

Heterogeneous aerobic benzene-degrading communities in oxygen-depleted groundwaters. FEMS Microbiol Ecol 58: 260-270.

Goyal AK \& Zylstra GJ (1996) Molecular cloning of novel genes for polycyclic aromatic hydrocarbon degradation from Comamonas testosteroni GZ39. Appl Environ Microbiol 62: 230-236.

Goyal AK \& Zylstra GJ (1997) Genetics of naphthalene and phenanthrene degradation by Comamonas testosteroni. J Indust Microbiol Biotechnol 19: 401-407.

Hendrickx B, Dejonghe W, Boënne W et al. (2005) Dynamics of an oligotrophic bacterial aquifer community during contact with a groundwater plume contaminated with benzene, toluene, ethylbenzene, and xylenes: an in situ mesocosm study. Appl Environ Microbiol 71: 3815-3825.

Hjort K, Lembke A, Speksnijder A, Smalla K \& Jansson JK (2007) Community structure of actively growing bacterial populations in plant pathogen suppressive soil. Microb Ecol 53: 399-413.

Isao Y, Hishinuma-Narisawa M, Hirota K, Shingyo T, Takebe F, Nodasaka Y, Matsuyama H \& Isao H (2004) Exiguobacterium oxidotolerans sp. nov., a novel alkaliphile exhibiting high catalase activity. Int J Syst Evol Microbiol 54: 2013-2017.
Johnsen A, de Lipthay JR, Sørensen SJ, Ekelund F, Christensen P, Andersen O, Karlson U \& Jacobsen CS (2006) Microbial degradation of street dust polycyclic aromatic hydrocarbons in microcosms simulating diffuse pollution of urban soil. Environ Microbiol 8: 535-545.

Johnsen A, Scmidt S, Hybholt TK, Henriksen S, Jacobsen CS \& Andersen O (2007) Strong impact on the polyaromatic hydrocarbon (PAH) degrading community of a PAH-polluted soil but marginal effect on PAH degradation when priming with bioremediation soil dominated with Mycobacteria. Appl Environ Microbiol 73: 1474-1480.

Kim E \& Zylstra GJ (1995) Molecular and biochemical characterization of two meta-cleavage dioxygenases involved in biphenyl and $m$-xylene degradation by Beijerinckia sp. strain B1. J Bacteriol 177: 3095-3103.

Kostka JE, Stucki JW, Nealson KH \& Wu J (1996) Reduction of structural Fe(III) in smectite by a pure culture of Schewanella putrefaciens strain MR-1. Clays Miner 44: 522-529.

Lauri AD \& Lloyd-Jones G (1999) The phn genes of Burkholderia sp. strain RP007 constitute a divergent gene cluster for polyaromatic hydrocarbon catabolism. J Bacteriol 181: 531-540.

Lauri AD \& Lloyd-Jones G (2000) Quantification of phnAc and nahAc in contaminated New Zealand soils by competitive PCR. Appl Environ Microbiol 66: 1814-1817.

Margalef R (1958) Information theory in ecology. Gen Sys 3: 36-71.

Martín-Gil J, Ramos-Sanchez MC \& Martin-Gil FJ (2004) Shewanella putrefaciens in a fuel-in-water emulsion from the Prestige oil spill. Antonie van Leeuwenhoek 86: 283-285.

Muñoz R, Guieysse B \& Mattiasson B (2003) Phenanthrene biodegradation by an algal-bacterial consortium in two-phase partitioning bioreactors. Appl Microbiol Biotechnol 61: 261-267.

Muyzer G, Teske A, Wirsen CO \& Jannasch HW (1995) Phylogenetic relationship of Thiomicrospira species and their identification in deep-sea hydrothermal vent samples by denaturing gradient gel electrophoresis of $16 \mathrm{~S}$ rDNA fragments. Arch Microbiol 164: 162-172.

Nealson KH, Moseder DP \& Saffarini A (1995) Anaerobic electron acceptor chemotaxis in Shewanella putrefaciens. Appl Environ Microbiol 61: 1551-1554.

Nogales B, Moore ERB, Abraham WR \& Timmis KN (1999) Identification of the metabolically active members of a bacterial community in a polychlorinated biphenyl-polluted mooreland soil. Environ Microbiol 3: 199-212.

Palm A, Wängberg I \& Broström-Lundén E (2001) Kvicksilver och organiska miljögifter i Örserumsviken, IVL Swedish Environmental Research institute Ltd. Report number B 1433.

Pizzul L, del Pilar Castillo M \& Stenström J (2006) Characterization of selected actinomycetes degrading polyaromatic hydrocarbons in liquid culture and spiked soil. World J Microbiol Biotechnol 22: 745-752.

Pritchard PH, Bourquin AW, Frederickson HL \& Maziarz T (1979) System design factors affecting environmental fate 
studies in microcosms. Workshop: Microbial degradation of pollutants in Marine environments (Bourqin AW \& Pritchard PM, eds), pp. 251-272, EPA-600/9-79-012. US Environmental Protection Agency, Washington, DC.

Sanseverino J, Applegate BM, King JMH \& Sayler GS (1993)

Plasmid-mediated mineralization of naphthalene, phenanthrene, and anthracene. Appl Environ Microbiol 59: 1931-1937.

Simon MJ, Osslund TD, Saunders R, Ensley BD, Suggs S, Harcourt A, Suen WC, Cruden DL, Gibson DT \& Zylstra GJ (1993) Sequences of genes encoding napthalene dioxygenase in Pseudomonas putida G7 and NCIB 9816-4. Gene 127: 31-37.

Singleton DR, Powell SN, Sangaiah R, Gold A, Ball LM \& Aitken MD (2005) Stable-isotope probing of bacteria capable of degrading salicylate, naphthalene or phenanthrene in a bioreactor treating contaminated soil. Appl Environ Microbiol 71: 1202-1209.

Singleton DR, Sangaiah R, Gold A, Ball LM \& Aitken MD (2006) Identification and quantification of uncultivated proteobacteria associated with pyrene degradation in a bioreactor treating PAH-contaminated soil. Environ Microbiol 8: 1736-1745.

Urbach E, Vergin LL \& Giovannoni SJ (1999) Immunochemical detection and isolation of DNA from metabolically active bacteria. Appl Environ Microbiol 65: 1207-1213.

Vishnivetskaya T, Kathariou S, McGrath J, Gilichinsky D \& Tiedje JM (2000) Low-temperature recovery strategies for the isolation of bacteria from ancient permafrost sediments. Extremophiles 4: 165-173.

Weisburg WG, Barns SM, Pelletier DA \& Lane DJ (1991) 16S Ribosomal DNA amplification for phylogenetic study. J Bacteriol 173: 697-703.

Whelan JA, Russel NB \& Whelan E (2003) A method for the absolute quantification of cDNA using real-time PCR. J Immunol Methods 278: 261-269.

Wilson MS, Herrick JB, Jeon CO, Hinman DE \& Madsen EL (2003) Horizontal transfer of phnAc dioxygenase genes within one of two phenotypically and genotypically distinctive naphthalene-degrading guilds from adjacent soil environments. Appl Environ Microbiol 69: 2172-2181. 